\title{
El Poblado Mínimo de Vallecas: espacio público, forma y materia
}

\author{
M. ${ }^{a}$ Teresa Gonzalez Vicario
}

El proceso de transformación urbana que se está operando en Madrid desde hace unos años supone, entre otros aspectos, la remodelación de zonas periféricas. Una de las necesidades más acuciantes se orienta a la consecución de un nuevo planteamiento de la vivienda social y a la mejora de los espacios públicos, en los que se hacen presentes diversas manifestaciones del arte de nuestro siglo.

El Poblado Mínimo de Vallecas, situado en Palomeras Bajas, dentro del Poligono de San Diego, es uno de los barrios periféricos de Madrid. Este barrio ', que se caracterizaba por sus graves carencias —casas degradadas, inhabitables, con necesidades de equipamiento y en las que se concentraban un excesivo número de familias- fue objeto de remodelación entre los años 1979 y $1987^{2}$. Un equipo de arquitectos, integrado por Mariano Calle, José Manuel Pazos y dos arquitectos designados por la Delegación del MOPU en Madrid, Jaime Alvear y Álvaro de la Peña, logró transformar este área urbana en un barrio en cuya urbanización se ha potenciado la necesidad de crear espacios públicos, ajardinados, aptos para la convivencia y en los que el escultor, el ceramista y el pintor han prestado su colaboración al arquitecto ${ }^{3}$.

El Poblado Mínimo de Vallecas fue construido en 1958 dentro del Plan de Urgencia Social de 13 de noviembre de 1957 por el arquitecto Luis Cubillo. Sus 672 viviendas fueron concebidas para alojar provisionalmente a un conjunto de familias, que con el tiempo se instalaron definitivamente en ellas, ordenadas según un trazado ortogonal con una plaza central como único espacio público.

${ }^{2}$ Esta remodelación se inscribe dentro de un proceso generado por la orden comunicada del Ministerio de Obras Públicas y Urbanismo (MOPU) de mayo de 1979.

${ }^{3} \mathrm{El}$ escultor Javier Aleixandre coordinó la labor realizada por un conjunto de artistas: los escultores Juan Bordes, Joaquin Rubio Camin y Jesús Valverde; el ceramista Arcadio Blasco; los pintores Ceferino Moreno y José Luis Pascual, junto a la paisajista Sylvia Decorde. Véase LeYva, Antonio, Javier Aleixandre. Madrid, EDARCON, 1988, pág. 74. 
Esta actividad artística se financió con el 1 por 100 del presupuesto de toda obra pública ${ }^{4}$, presupuesto, por otro lado, bastante modesto, por lo que debe señalarse el entusiasmo y también el desinterés de todos los artistas que colaboraron en el proyecto. Su desarrollo tuvo lugar en dos fases ${ }^{5}$. En la primera de ellas se construyó un bloque de viviendas de trece plantas que constituye el principal del conjunto. Con objeto de dotar a este proyecto de una significación plástica se recurrió a la integración del lenguaje escultórico en el entorno arquitectónico, a través, en esta primera fase, de dos obras que ocupan los extremos del soportal del edificio, realizadas por Javier Aleixandre y Jesús Valverde.

En la segunda fase, entre los espacios edificados aparecen otros libres de uso público - la plaza, la plaza-jardín y el recinto peatonal-, zonas claramente diferenciadas (fig. 1), pensadas para la convivencia y los juegos de los niños, y en las que se destacan diversas interpretacio-

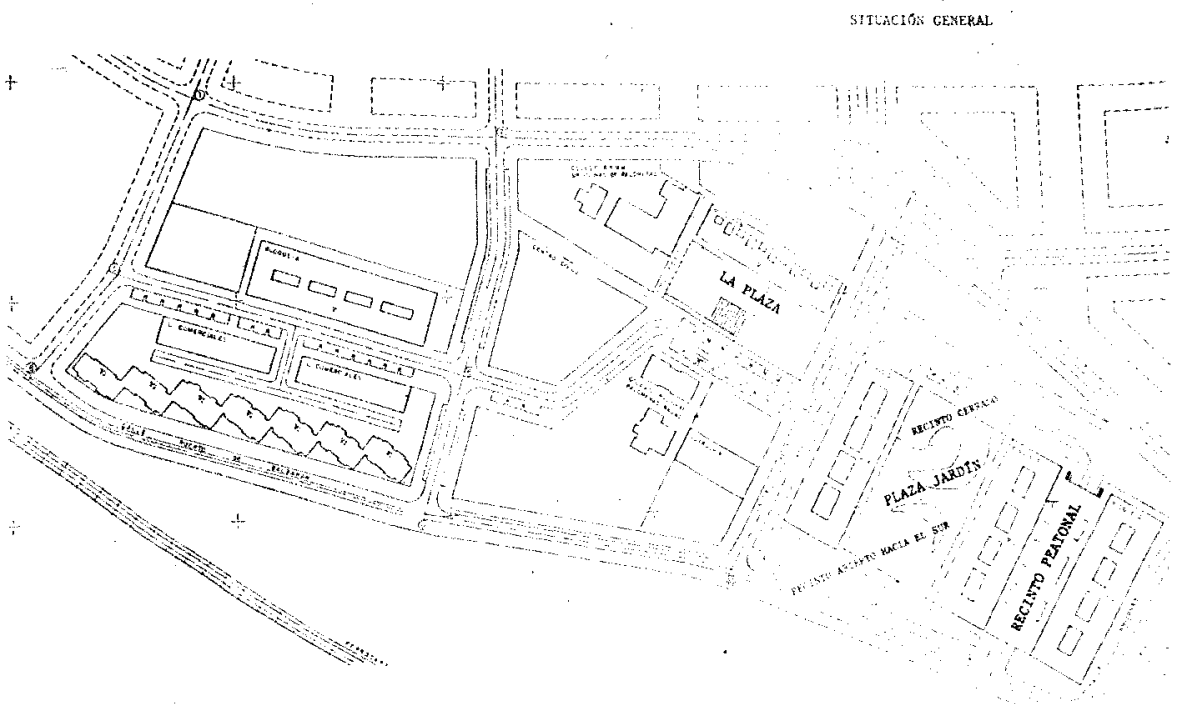

Fig. 1. Planta general de situación (Fuente: Plan de Reforma Interior del Poblado Mínimo de Vallecas)

\footnotetext{
${ }^{4}$ Real Decreto $2838 / 78$ del 27 de octubre sobre el 1 por. 100 cultural, actualmente transformado por el $111 / 86$.

${ }^{5}$ Comes, Vicente, "Todos en el ajo", MOPU, Revista del Ministerio de Obras Públicas y Urbanismo, núm. 354,1988 , págs. $64-69$.
} 
nes de la forma plástica como resultado de la actividad artística de Joaquin Rubio Camin y Javier Aleixandre en la plaza, de Arcadio Blasco y Juan Bordes en la plaza-jardín, de Ceferino Moreno en el recinto peatonal $y$, finalmente, de José Luis Pascual, que en fecha más reciente ha decorado una de las fachadas de un bloque de viviendas que limita una plaza no realizada todavia.

Frente a la plaza-jardin se levanta el bloque de viviendas de trece plantas, construido durante la primera fase del proyecto, y cuyo soportal alberga, como se dijo anteriormente, dos esculturas realizadas por Javier Aleixandre y Jesús Valverde, Homenaje a Goya y Figura femenina respectivamente ${ }^{6}$.

En Homenaje a Goya ${ }^{7}$, obra de 1980 e inspirada en La maja desnuda, la figura, de tamaño natural, se rompe longitudinalmente en dos mitades (fig. 2), sin que ello suponga la eliminación de sus elementos descriptivos. Javier Aleixandre nos ofrece en ella una personal interpretación de la figura humana, integrada por dos piezas de ritmos sinuosos, que se acoplan armoniosamente, a la vez que permiten penetrar al espacio entre ambas. Aunque manteniéndose fiel a la realidad figurativa, tiende a la simplificación formal, a la valoración de los volúmenes, de tersas superficies, en los que se subrayan los juegos de luces y sombras, que acentúan la plasticidad formal. El protagonismo que lo curvilineo tiene en el conjunto, se hace más patente con ia presencia de dos aros de acero paralelos, cuyo diámetro excede los dos metros, y que acogen con ritmo envolvente a la figura, ejecutada en bronce pulido y patinado, y suspendida en el espacio por unos tensores.

En el extremo opuesto del soportal, se levanta sobre un pedestal la obra titulada Figura femenina, realizada por Jesús Valverde en bronce, en 1983 (fig. 3). Hay en ella una marcada monumentalidad como consecuencia no sólo de su tamaño -mide $1,80 \mathrm{~m}$ aproximadamente-, sino también de los rotundos volúmenes del cuerpo, en cuyo planteamiento se advierten deformaciones intencionadas, que subrayan la arquitectura de su masa, en la que se confunden lo figurativo y lo abstracto. La intensidad formal de esta obra está más señalada por el espacio que por la materia,

\footnotetext{
${ }^{6}$ En el Museo Municipal de Madrid se conserva una reproducción (0,30 m apróx.) de estas dos obras.

'La primera versión de esta obra, ejecutada en poliéster, fue una de las presentadas por Javier Aleixandre en la Bienal de Venecia de 1980, y estuvo situado junto a la titulada Rotacional Humano en la entrada del Pabellón de España. LeYva, Antonio, ob. cit., págs. 44 y 45. Catálogo Exposición Javier Aleixandre. Transformables, cartones, esculturas. Museo Juan Barjola. Gijón, 8 de marzo - 7 de abril de 1991, págs. 9 y 10.
} 


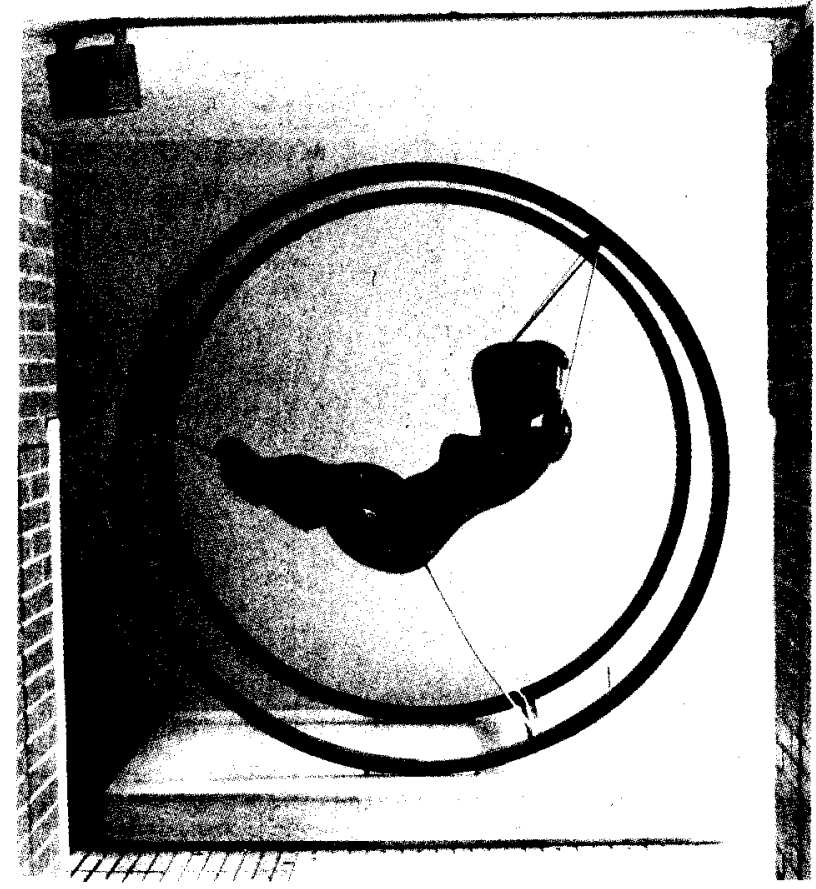

Fig. 2. Javier Aleixandre, Homenaje a Goya

puesto que el primero sugiere, incluso podria decirse que hace presente, lo no representado, pero sin verse encerrado en unos limites concretos. No es una obra monolítica, de estructura cerrada, sino que su abierta corporeidad supone la expresión de un particular lenguaje, un lenguaje con el que el escultor expresa a través de la fusión de la materia y del espacio la vinculación de la Mujer con la Naturaleza.

Mientras estas dos obras se encuentran oprimidas por los límites arquitectónicos del soportal, en la segunda fase la ordenación de los bloques de viviendas y de los espacios públicos comprendidos entre ellas, abrió un amplio campo de posibilidades para la integración de diversas realizaciones plásticas en su entorno.

El primero de estos espacios públicos anteriormente mencionados, la plaza, es de grandes dimensiones y presenta dos niveles claramente diferenciados, pero, al mismo tiempo, complementarios y articulados a través de un muro-escalera y de una rampa-escalera. El más elevado de dichos niveles es una plataforma, que sirve como prolongación del área de soportales de un edificio limitrofe; el inferior, por el contrario, se abre directamente a la calle. Ocupando el centro de la plaza y en el limite de 


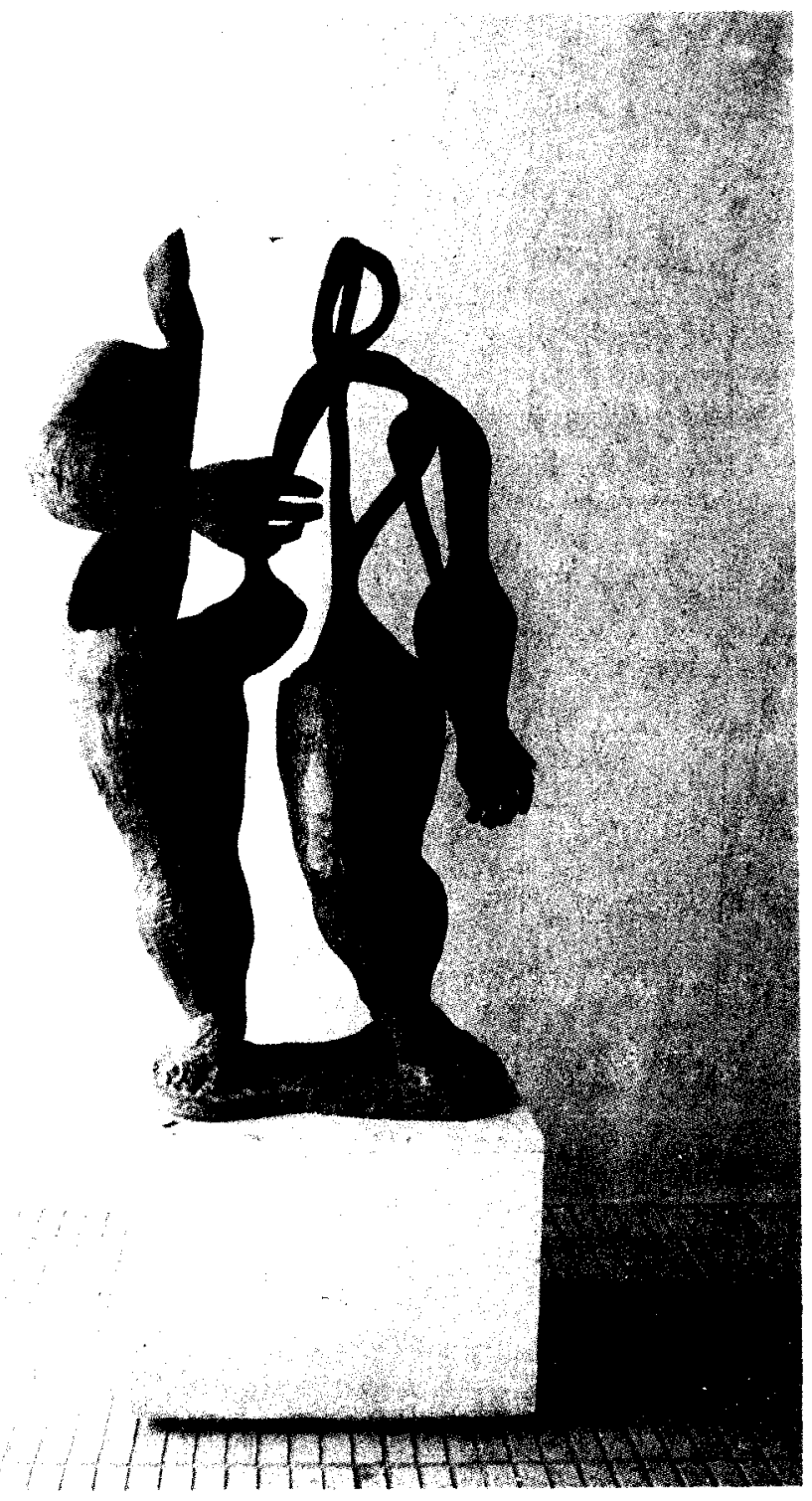

Fig. 3. Jesús Valverde, Figura femenina 
la superficie más elevada, se levanta un grupo escultórico de grandes dimensiones, realizado en ladrillo macizo, en 1986, por Joaquin Rubio Camín y Javier Aleixandre (fig. 4).

Ambos escultores han sabido aunar en esta obra en común sus diferentes estilos, participando de un mismo material, pero creando unas formas que aunque opuestas, se complementan ${ }^{8}$. El ladrillo, dispuesto en hiladas y posteriormente tallado, ha sido transformado por Camín en un bloque monolítico, de superficies suavemente onduladas, y en el que se destacan los sobrios volúmenes de una figura femenina, que acompañada por otras dos infantiles constituyen una Maternidad (fig. 5). En ella ${ }^{9}$ el detalle se subordina a lo esencial, enfatizándose la monumentalidad del volumen, de estructura cerrada, que en algunas zonas sugiere más que representa la realidad anatómica ${ }^{10}$.

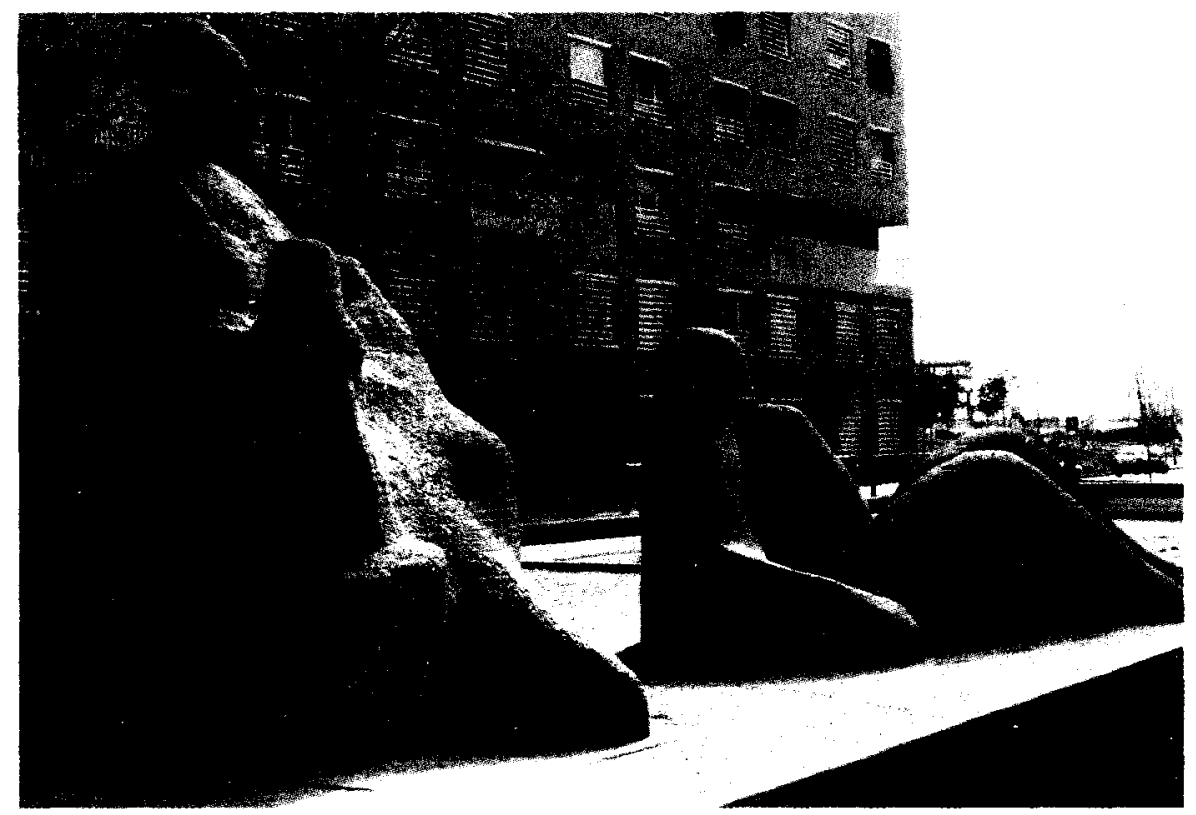

Fig. 4. Joaquin Rubio Camin y Javier Aleixandre, Familia

${ }^{8}$ LeYva, Antonio, ob. cit., págs. 74, 76 y 79.

${ }^{9}$ Es de lamentar la degradación que estas obras han sufrido con el tiempo como consecuencia de comportamientos poco civicos, pudiendo servir de ejemplo la comparación de las figuras 4 y 5 .

10 Alvarez Martinez, M. ${ }^{a}$ Soledad, Camín escultor. Oviedo, Caja de Ahorros de Asturias,

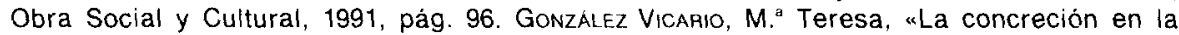
escultura de Camin», Goya, núm. 219, 1990, pág. 158. 


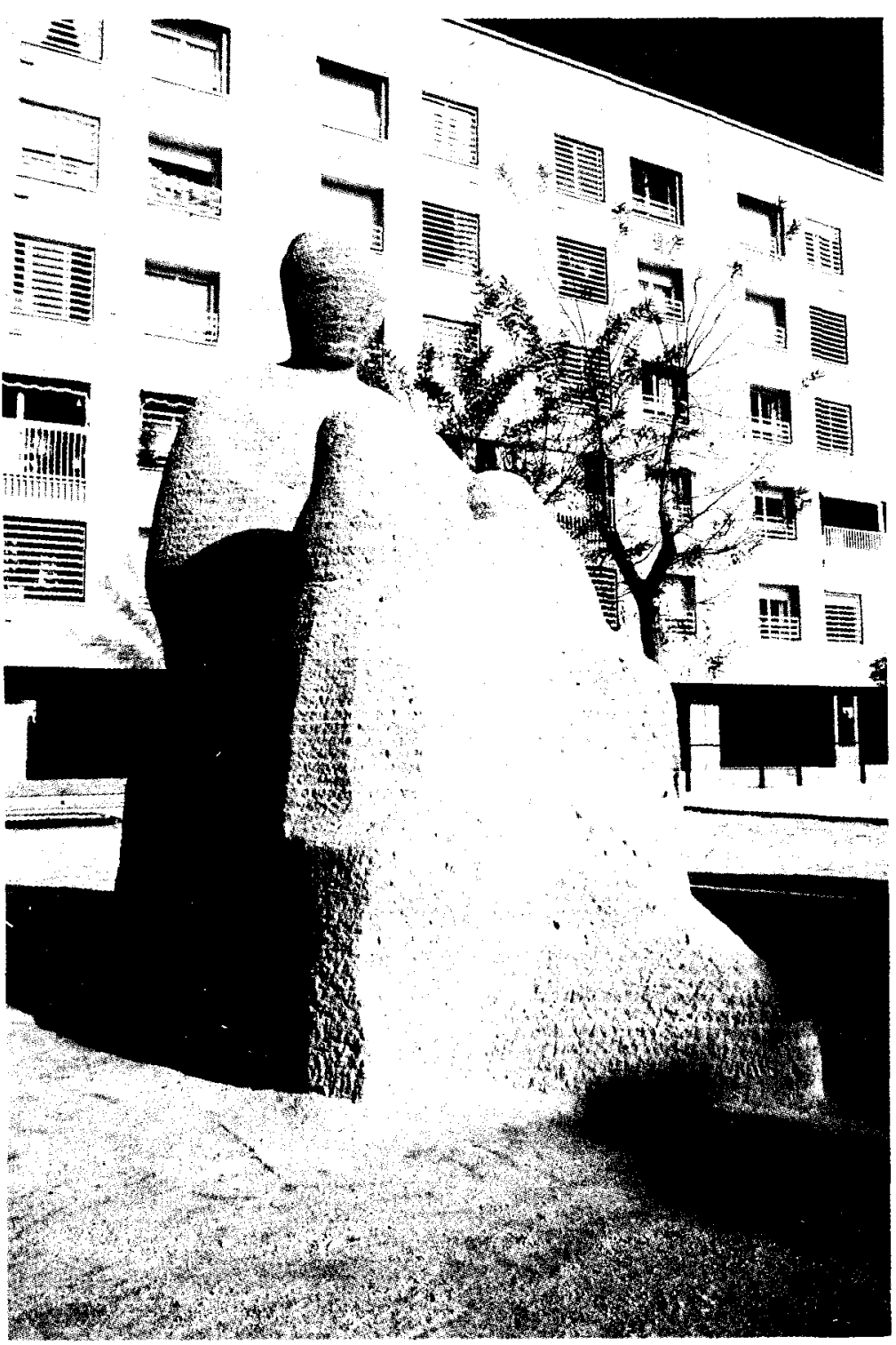

Fig. 5. Joaquin Rubio Camin, Maternidad 
Frente a la unidad formal que se aprecia en esta Maternidad, Aleixandre sigue un planteamiento muy distinto en la Figura masculina (fig. 6) que completa este grupo escultórico. La obra constituye una estructura organizada en varios módulos entre los que fluye el espacio, originando una solución formal más abstracta que figurativa. Sin embargo, esta subjetiva interpretación del cuerpo masculino, a través del agrupamiento de unos módulos, no supone la total ruptura con la figuración, latente en el conjunto, sino el enriquecimiento del lenguaje formal de esta obra. La fragmentación de la materia (fig. 7) se complementa con el vacio que la circunda, adquiriendo un carácter lúdico, que atrae al espectador, a la vez que le invita a recorrer los espacios que separan los rigurosos volúmenes en los que ha sido fragmentada la figura, para ir descubriendo los cambiantes aspectos que le ofrece esta realización escultórica, cuya solución formal, basada en la fragmentación de la materia, es la armónica respuesta al rotundo y cerrado volumen de la Maternidad de Camín.

La plaza-jardín, el segundo de los espacios públicos mencionados con anterioridad, ha sido dividida en dos zonas: el recinto cerrado y el recinto abierto hacia el sur. Aunque perfectamente individualizados, ambos recintos se complementan, originando unos relieves artificiales, de formas si-

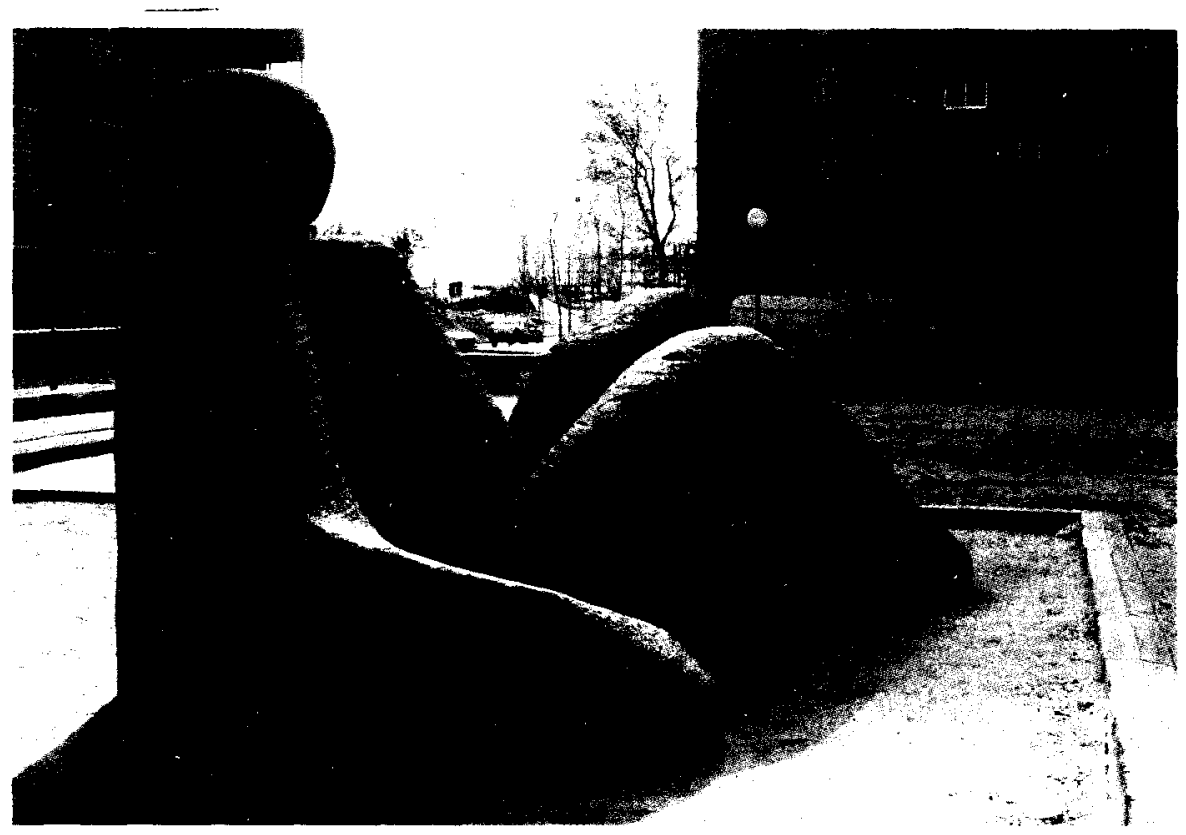

Fig. 6. Javier Aleixandre, Figura masculina 


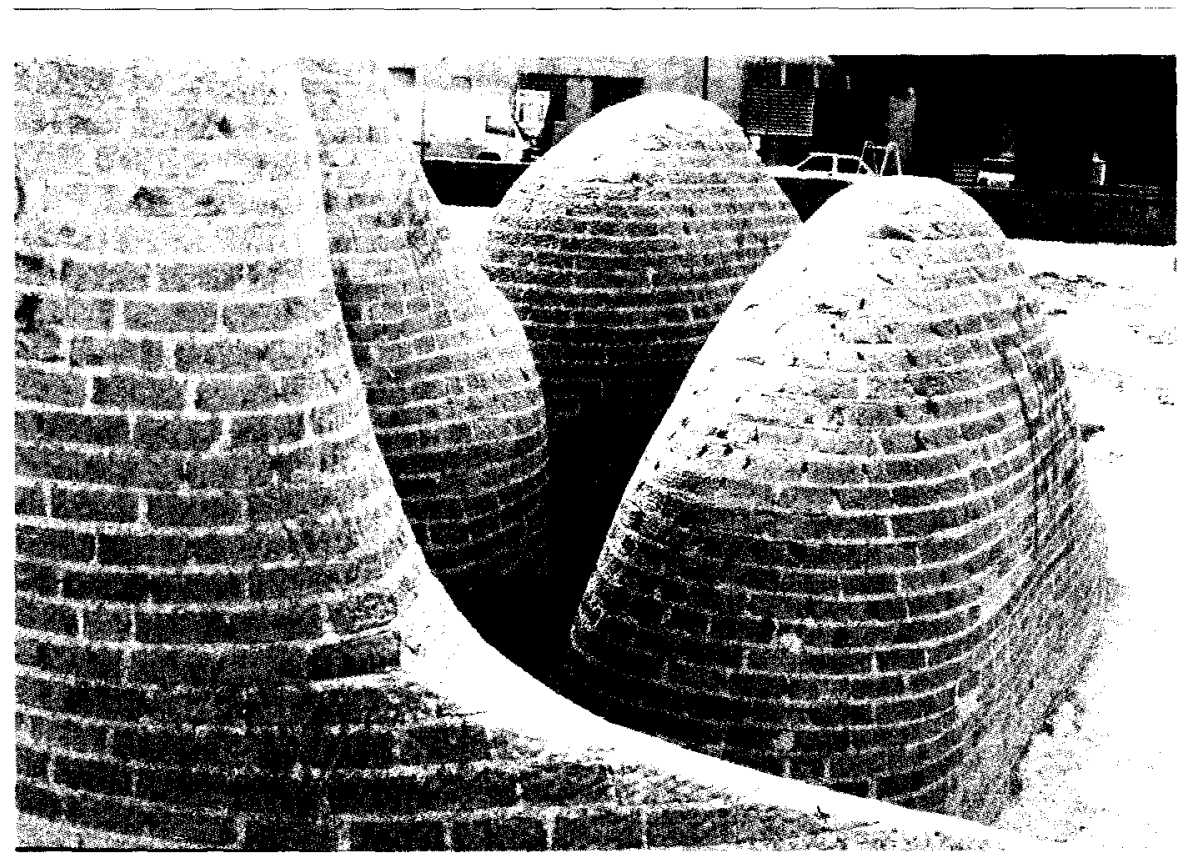

Fig. 7. Detalle

nuosas, sugerentes, con sendas adoquinadas y en los que crece la vegetación, que presta un mayor atractivo al conjunto.

El espacio del recinto cerrado se encuentra limitado por uno de los relieves artificiales, que adopta la forma de un cráter y rodea con su ritmo envolvente una obra de Arcadio Blasco, titulada Monumento a un personaje importante ". Dicha obra (figs. 8 y 9), realizada en cerámica refractaria en 1985 , mide aproximadamente $3,50 \mathrm{~m}$. Se levanta sobre un doble basamento de piedra y cerámica, que presta una cierta monumentalidad a esta escultura, en la que Arcadio Blasco ha querido resaltar la creatividad infantil, su espontáneo lenguaje plástico. La materia se ha transformado en unos toscos volúmenes de contornos precisos, aplomados, para originar un personaje imaginado, que se yergue sobre un pedestal cerámico con marcado frontalismo y con la altivez suficiente como

"Para la realización de esta obra Arcadio Blasco buscó la colaboración de los colegios de la zona -Palomeras Bajas, Virgen de Guadalupe y Ursulinas de Palomeras-, cuyos alumnos de menor edad presentaron unos bocetos representando la escultura que, a su entender, debería ocupar el espacio del recinto cerrado. Los elegidos fueron ampliados por los alumnos de mayor edad en el estudio del ceramista, hasta que finalmente fue seleccioriado el definitivo. 


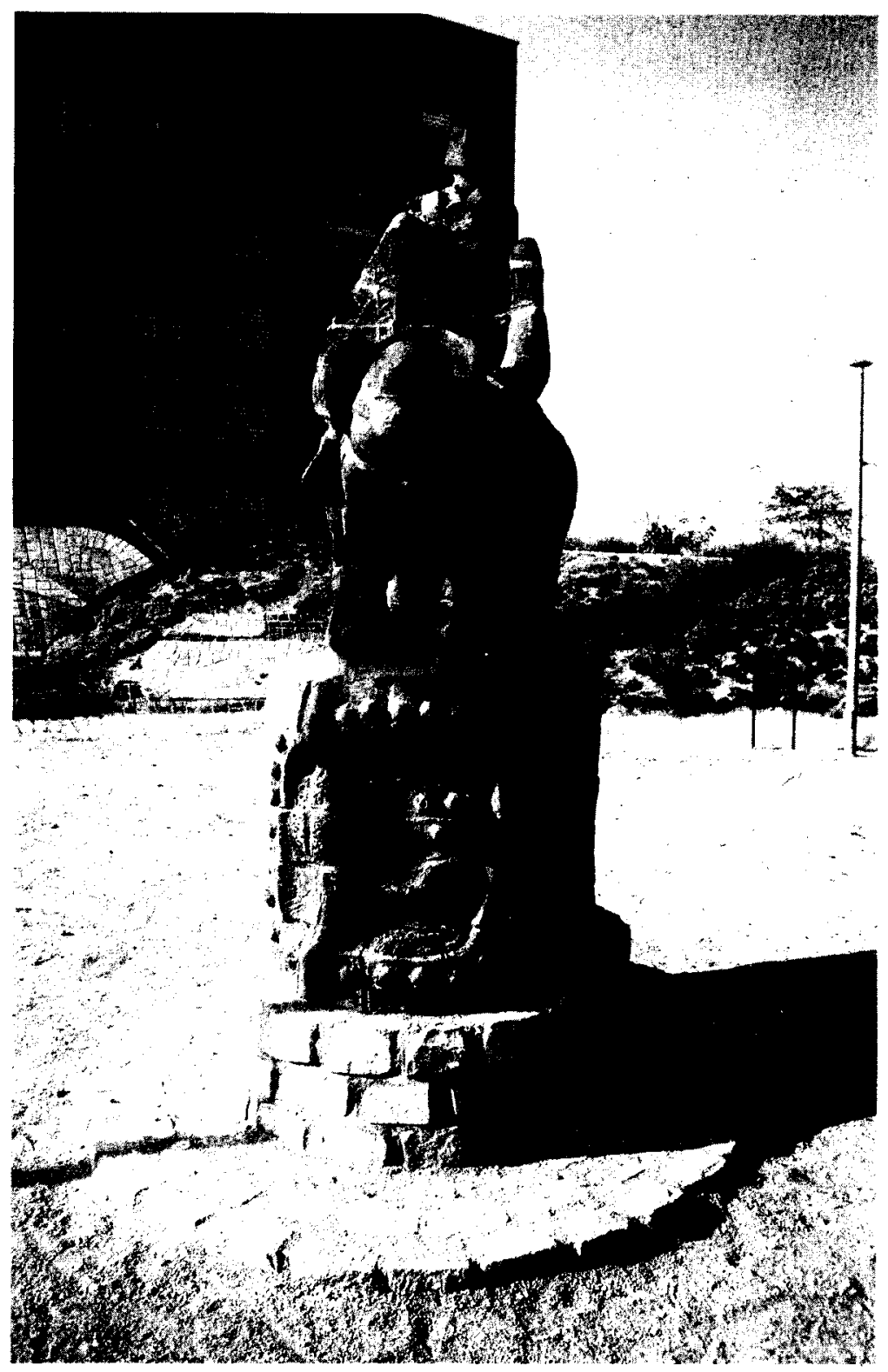

Fig. 8. Arcadio Blasco, Monumento a un personaje importante 


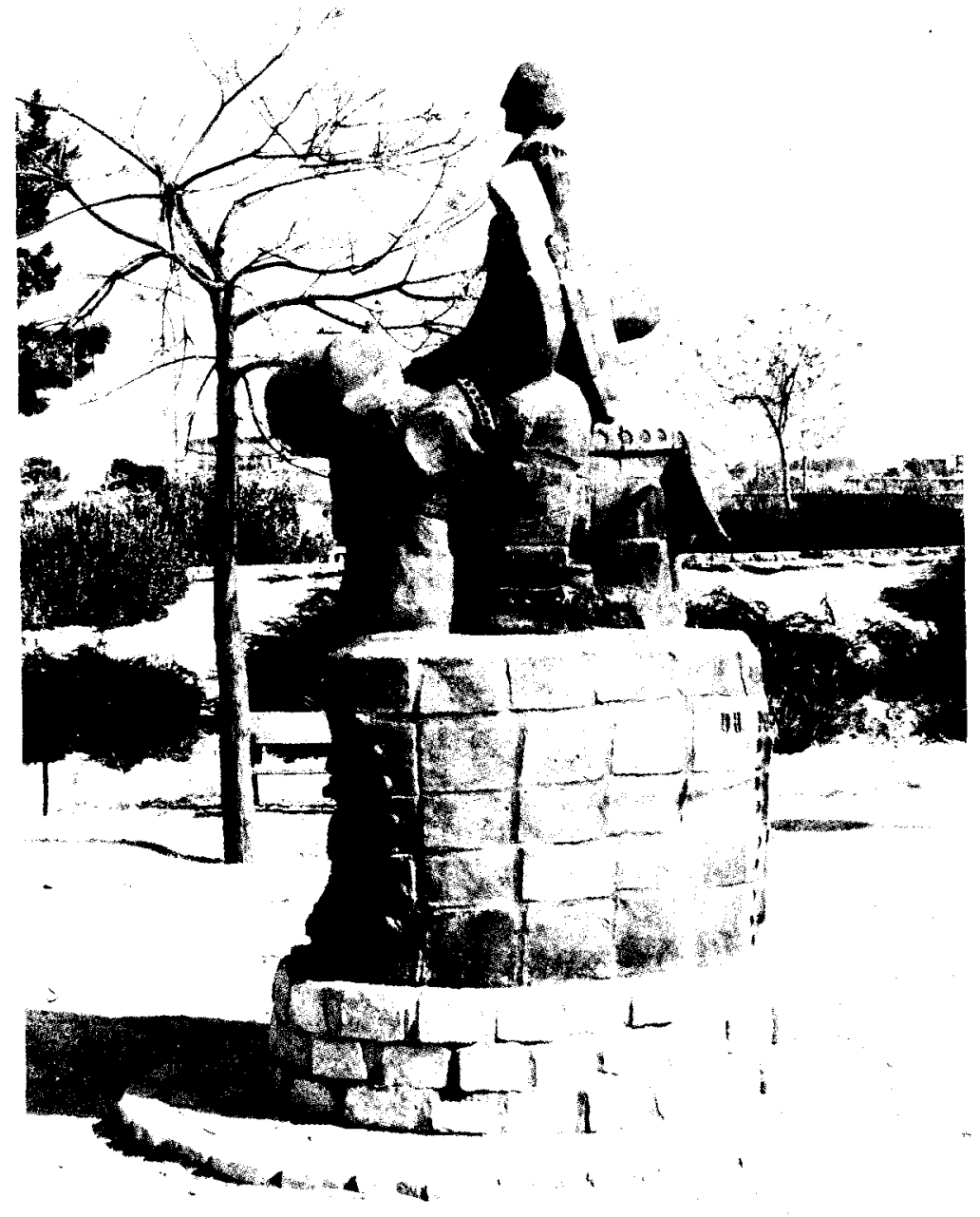

Fig. 9. Arcadio Blasco, Monumento a un personaje importante 
para evocar, siempre desde la mentalidad infantil, un sinfín de aventuras y de hazañas inimaginables por él realizadas. Alejado del mundo de los adultos y, sin embargo, ocupando un lugar "real» en el de los niños, este personaje se ha materializado en esta obra, una obra auténtica, entrañable, y quizá la más adecuada por su significación para presidir los diarios juegos infantiles. El oso y el madroño ocupa el centro del pedestal en su parte frontal, mientras que en la zona opuesta hay una inscripción con el nombre de los colegios y de los alumnos que han contribuido en la realización de esta obra.

Arcadio Blasco es el autor de un mural $(9,00 \times 5,00 \mathrm{~m}$ apróx.) que se integra en la tierra, y se confunde con el relieve artificial, que en forma de cráter enmarca el recinto cerrado (figs. 10 y 11). Este mural, que adopta la apariencia de unos restos arqueológicos, de algo que no se impone sino que se descubre, ha sido pensado para motivar los juegos infantiles. Realizado en el mismo año que la anterior obra, las piezas de cerámica refractaria, de tonalidad gris, verde, blanca y ocre, originan unas formas irregulares, que aparecen y desaparecen para volver a reaparecer, confundiéndose con la vegetación y fundiéndose con la tierra, para subrayar la inclinación de la ladera del cráter y originar lo que podría considerarse

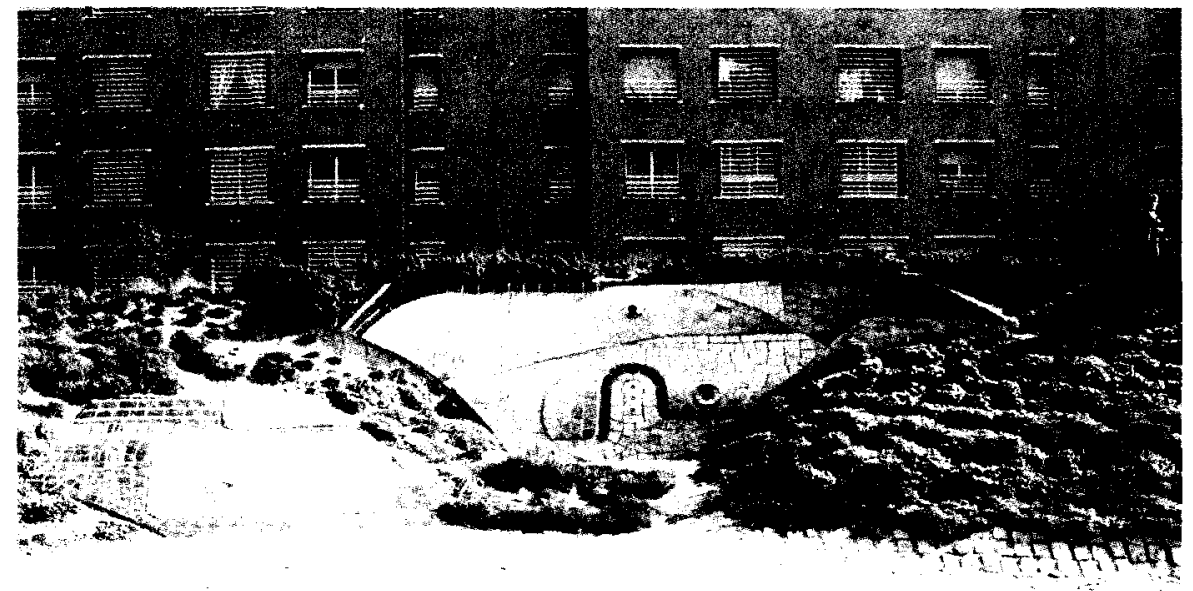

Fig. 10. Arcadio Blasco, Mural 


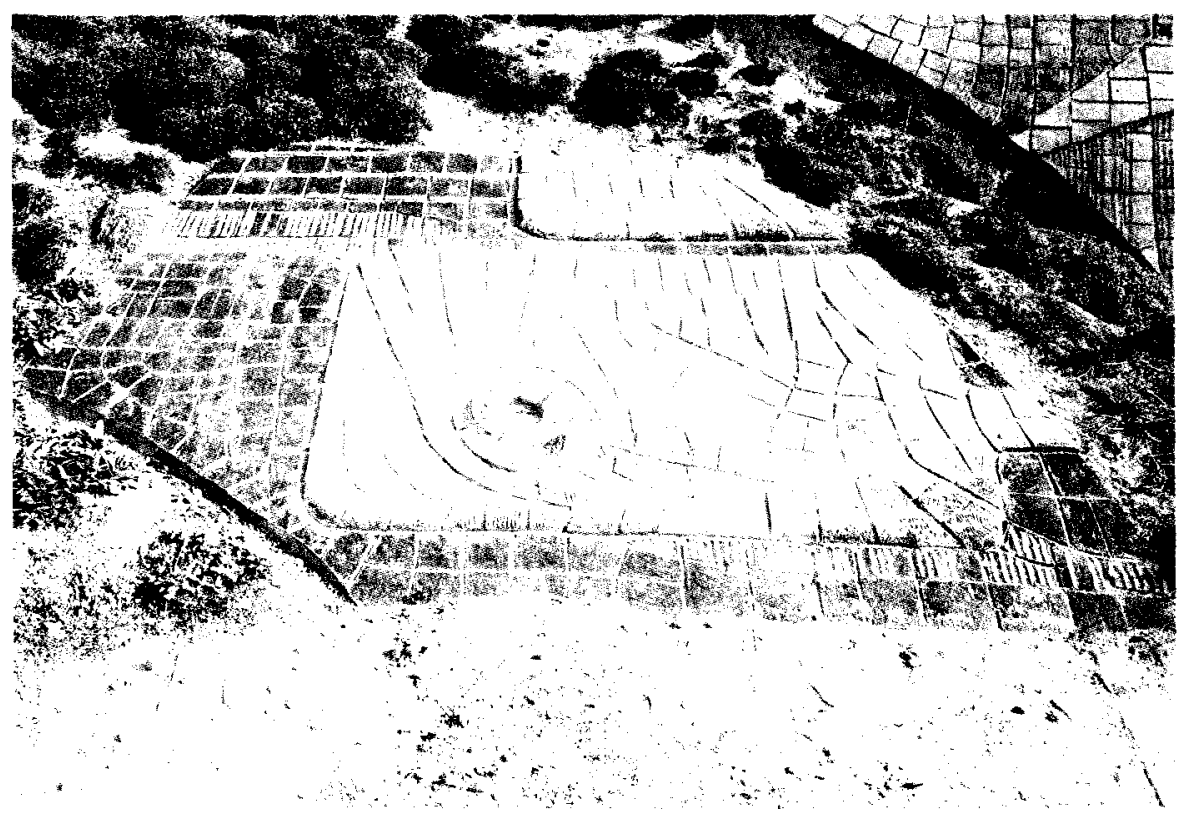

Fig. 11. Detalle

como un mural-paisaje, que embellece la artificial presencia de la naturaleza en el entorno urbano.

El recinto abierto hacia el sur de la plaza-jardín ha sido concebido como lugar destinado a diferentes actividades culturales. Su estructura, de clara inspiración clásica, queda definida por otro relieve artificial que también describe una forma curvilinea, en cuya parte cóncava están incrustadas unas gradas, orientadas hacia un espacio semicircular.

En uno de los extremos de dicho relieve artificial y sobre un muro de hormigón, se encuentra la figura de Diana en actitud de huir de un animal (fig. 12). Juan Bordes, sirviéndose del bronce y del acero, no ha pretendido representar el mito de Diana; por el contrario, los personajes integrantes de esta obra, que data de 1984, carecen del significado que tradicionalmente se les ha dado. El escultor se aleja del mito, generalmente no conocido por el hombre de la calle, para crear un "mito cotidiano", cuyo contenido es conscientemente ambiguo, pero sugerente, capaz de intrigar al transeunte hasta incitarle a imaginar una historia, que será su propia historia, en la que cada personaje tendrá el nombre que él le dé. 


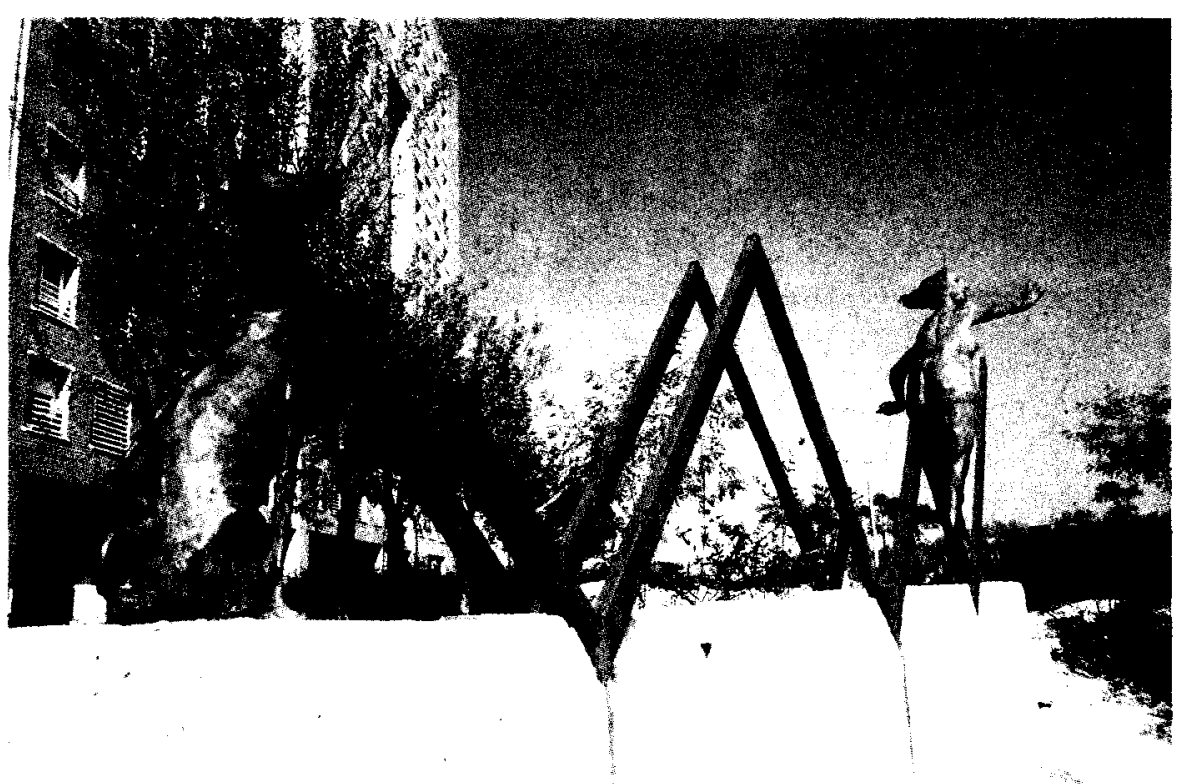

Fig. 12. Juan Bordes, Diana

Forma y materia en las dos figuras -la de Diana, que mide $2 \mathrm{~m}$, y la del perro que la acompañaba ${ }^{12}$, de $0,70 \mathrm{~m}$ apróx. - transmiten un lenguaje plástico de raíz clásica. La nota dominante en el conjunto supone la oposición del amenazante estatismo del perro (fig. 13) frente al acusado dinamismo del cuerpo de Diana (fig. 14), un dinamismo que por un lado sugiere la idea de la huida, pero por otro es un recurso utilizado por Juan Bordes para "agrandar» el tamaño de la obra, a través de ese amplio gesto con el que la figura ocupa el espacio a base de un movimiento potencial.

Los dibujos preparatorios (figs. 15 y 16) reflejan algunas variantes en el planteamiento de este conjunto escultórico ${ }^{13}$, en el que no debe minimizarse la significación del perro, personaje agresivo, peligroso, cuyo maleficio se simboliza por medio de las líneas quebradas que enlazan las dos figuras, distanciadas entre si aproximadamente unos seis metros, y en cuyas formas anatómicas se evidencia una personal interpretación del lenguaje clásico, que incita al espectador a recrear un mito a través de

\footnotetext{
${ }^{12}$ Actualmente no se conserva esta figura por haber sido robada.

${ }^{13}$ Bordes, Juan, Dibujos 1984-1987. Estudios y proyectos de escultura monumental. La Laguna (Tenerife), Conca Ediciones, 1988 (s.p.).
} 


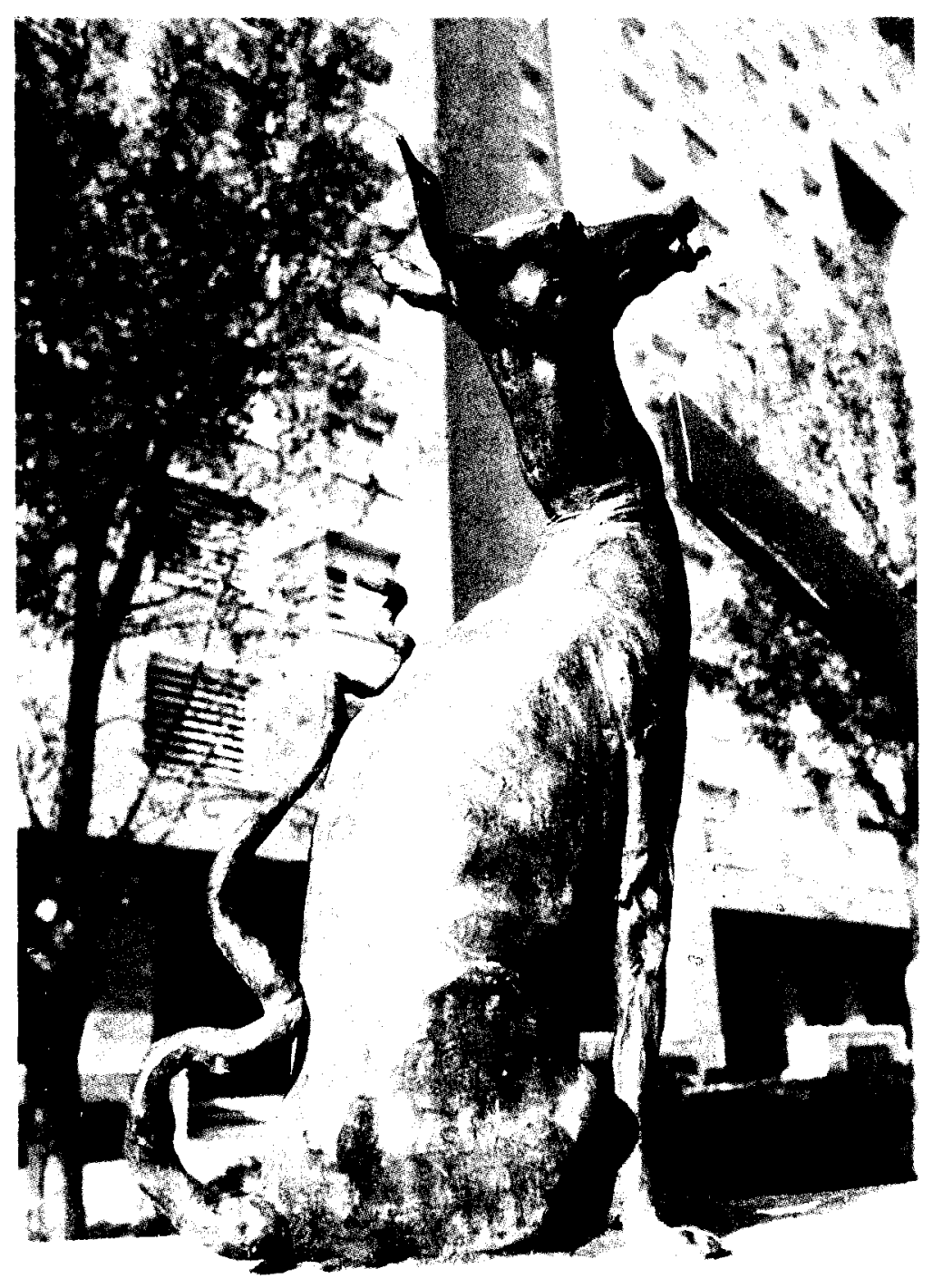

Fig. 13. Detalle 


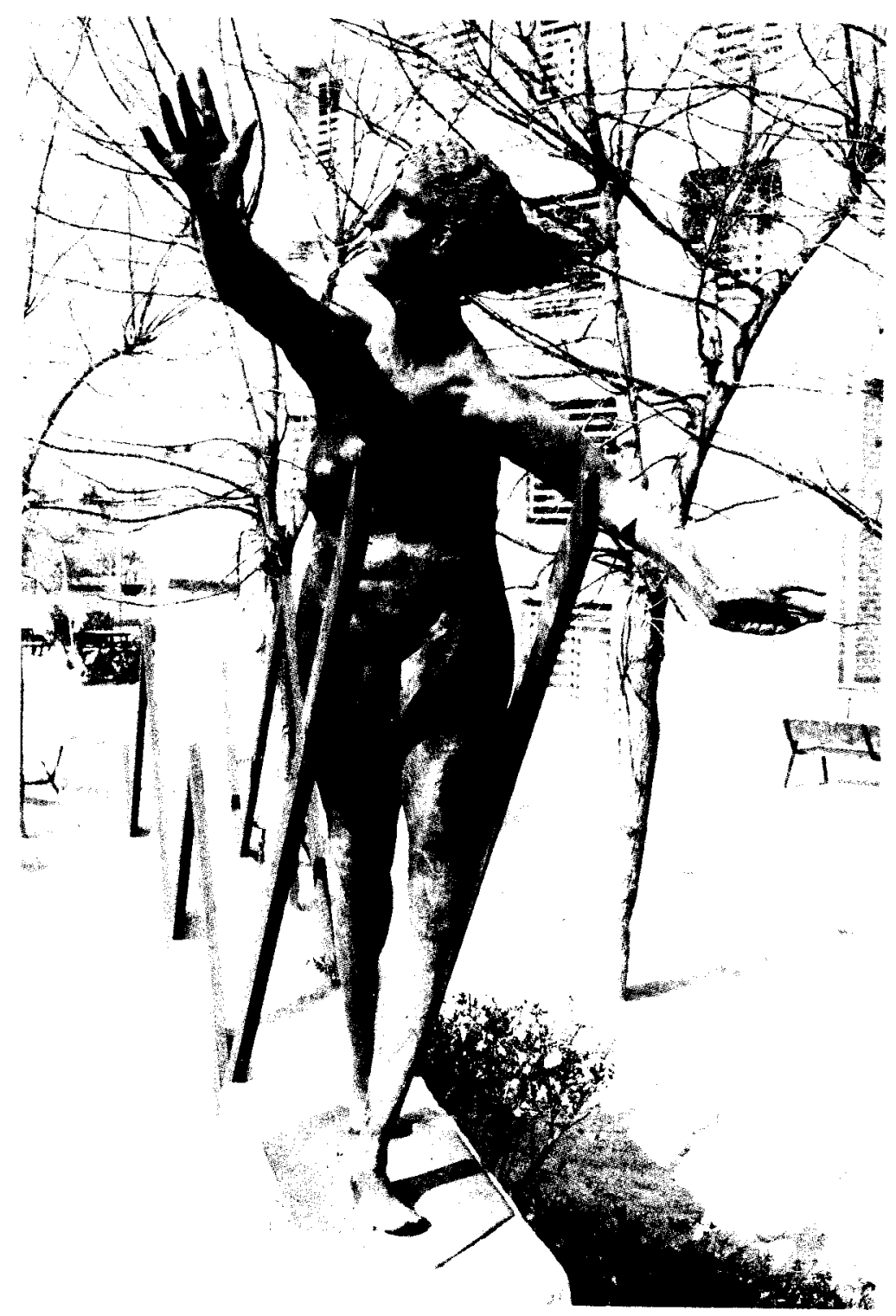

Fig. 14. Detalle 


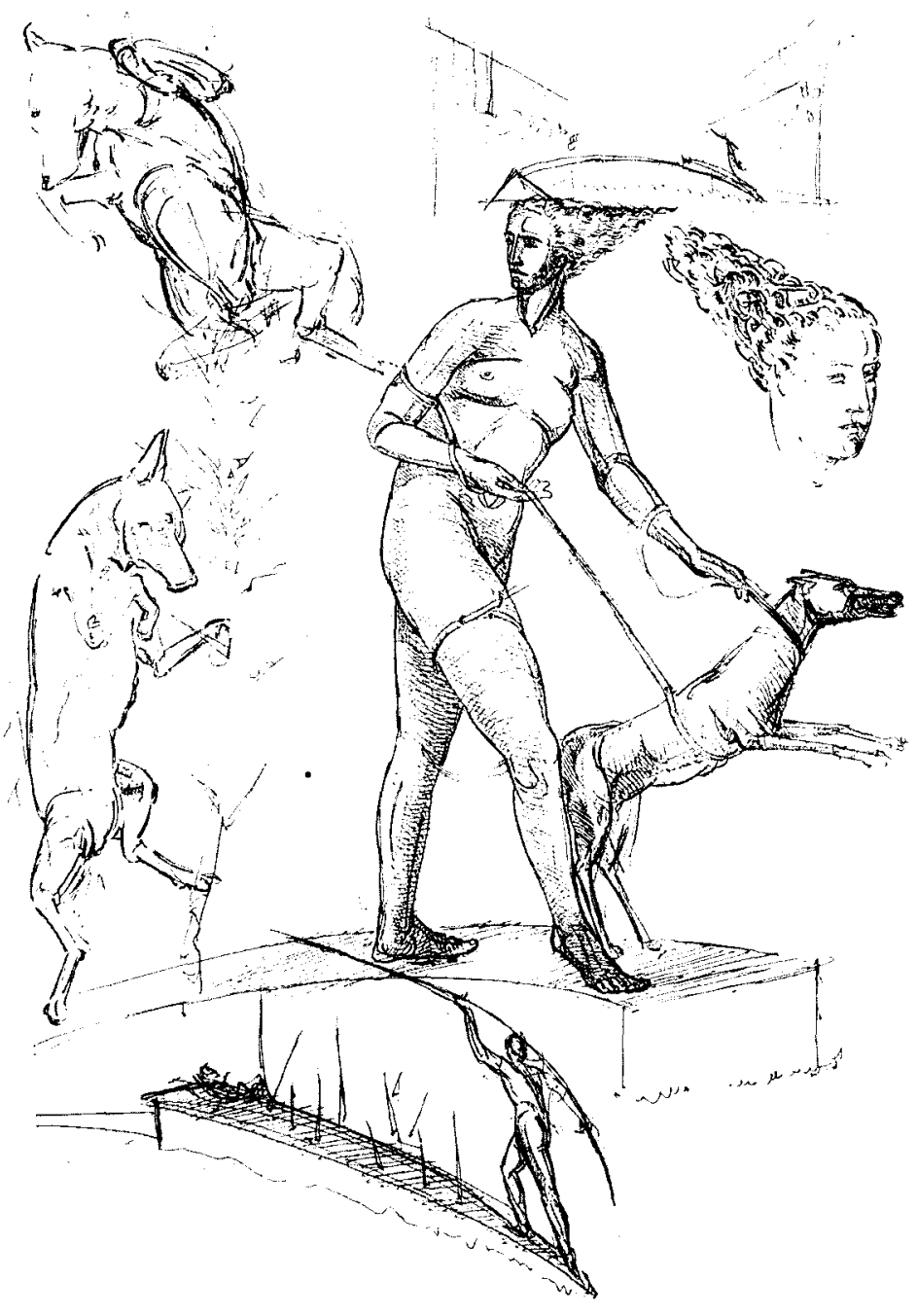

Fig. 15. Juan Bordes, Diana (dibujos preparatorios) 


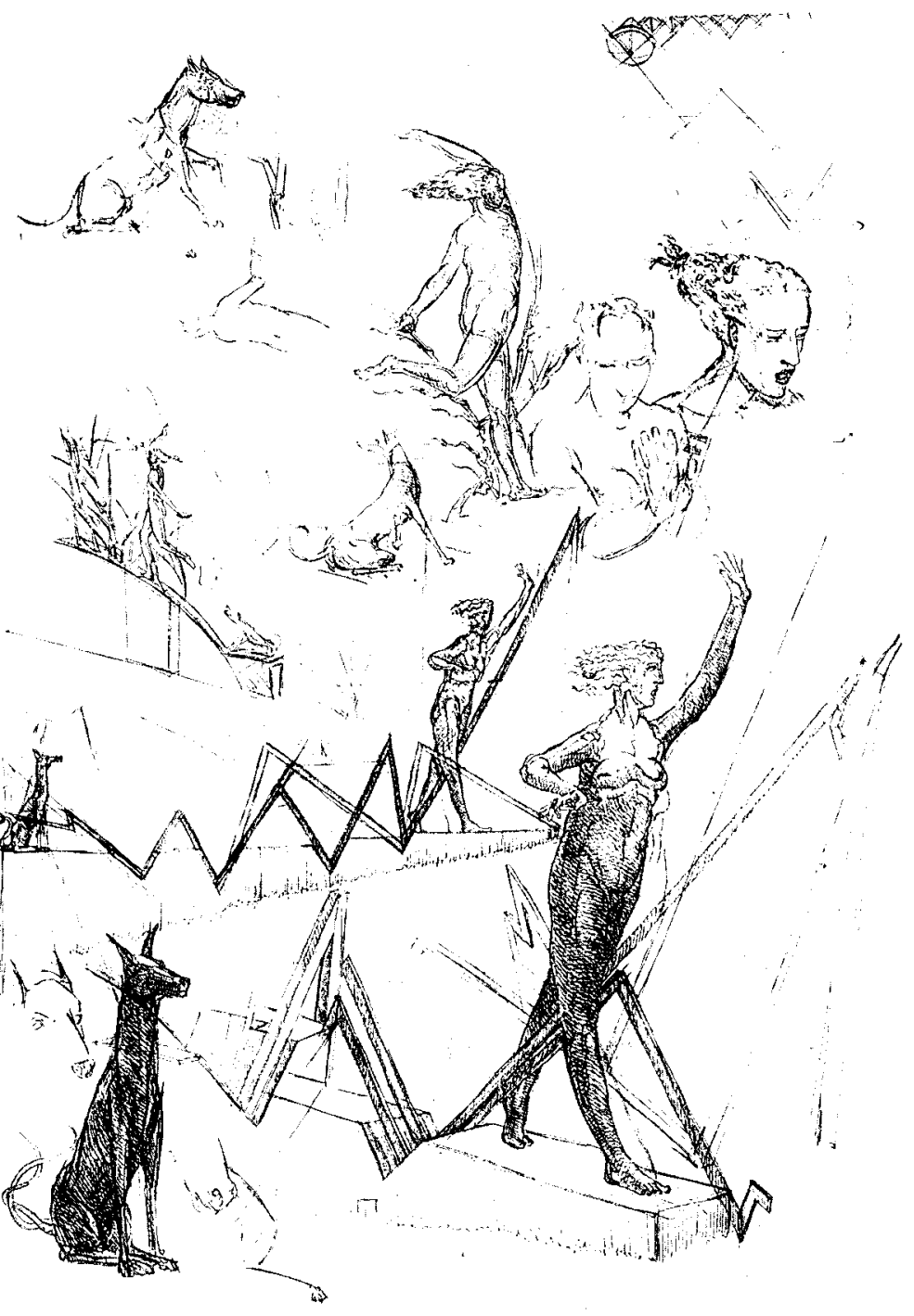

Fig. 16. Juan Bordes, Diana (dibujos preparatorios) 
la ambigüedad, palabra clave, en opinión de Juan Bordes, al ser "ella la que hace divergentes las interpretaciones. La que hace ricos y contradictorios los disfrutes. La que hace múltiples las apropiaciones. La que hace creativa la contemplación. Y es, en definitiva, la que privatiza los descubrimientos del espectador" ${ }^{14}$.

El recinto peatonal supone un gran espacio de proporciones rectangulares, situado sobre el garaje y limitado por seis jardineras de considerable tamaño, en las que se acoplan unos bancos corridos. En este espacio público se ha dado al pavimento un señalado protagonismo, en el que la materia -terrazo, mármol negro de Calatorao (Zaragoza) y terrazo con arenas de mármol blanco de Macael (Almeria) - origina unas formas plásticas que representan una alegoria del Orden cósmico $(86 \mathrm{~m}$ $\times 27 \mathrm{~m}$ apróx.). Ceferino Moreno, al igual que los restantes artistas, ha gozado de una total libertad para concebir su obra ${ }^{15}$. Como gran aficionado a la astrologia, escogió este tema para decorar el pavimento de un lugar de encuentros, de un lugar que puede ser el escenario de las más variadas actividades públicas, para lo cual compartimentó la totalidad del espacio en otros más pequeños, tomando como pretexto los simbolos planetarios del sistema solar (figs. 17 y 18)..

Los diferentes espacios quedan perfectamente definidos por los contrastes cromáticos y por la presencia de la geometria de unas formas, unas formas que representan al sol, situado en uno de los extremos, y a los planetas $(6,00 \mathrm{~m} \times 7,00 \mathrm{~m}$ cada uno apróx.), estos últimos organizados según la distancia que tienen respecto al sol, sin que se haya pretendido una relación geométrica, pero si de situación.

La armonía de este espacio público radica en la correcta adecuación de las jardineras, los bancos y un pavimento en el que se destacan unas líneas orbitales, que obedeciendo a un planteamiento puramente estético, dinamizan un conjunto en el que cada elemento se encuentra perfectamente integrado. Los ritmos circulares y ovalados se contraponen al ritmo rectangular de la plaza, que se repite en las jardineras, originándose un juego formal, equilibrado y armónico.

Además de la plaza, la plaza-jardín y el recinto peatonal, debe señalarse to que en un futuro será otro espacio público, concretamente una plaza, situada en una zona no concluida todavia, y que supondrá la finalización de esta segunda fase.

${ }^{i 4}$ Bordes, Juan, La figura: teatro y paisaje. Las Palmas de Gran Canaria, Edirca, 1991, pág. 22.

${ }^{15}$ El boceto definitivo ha sido regalado por Ceferino Moreno al Museo Municipal de Madrid. 


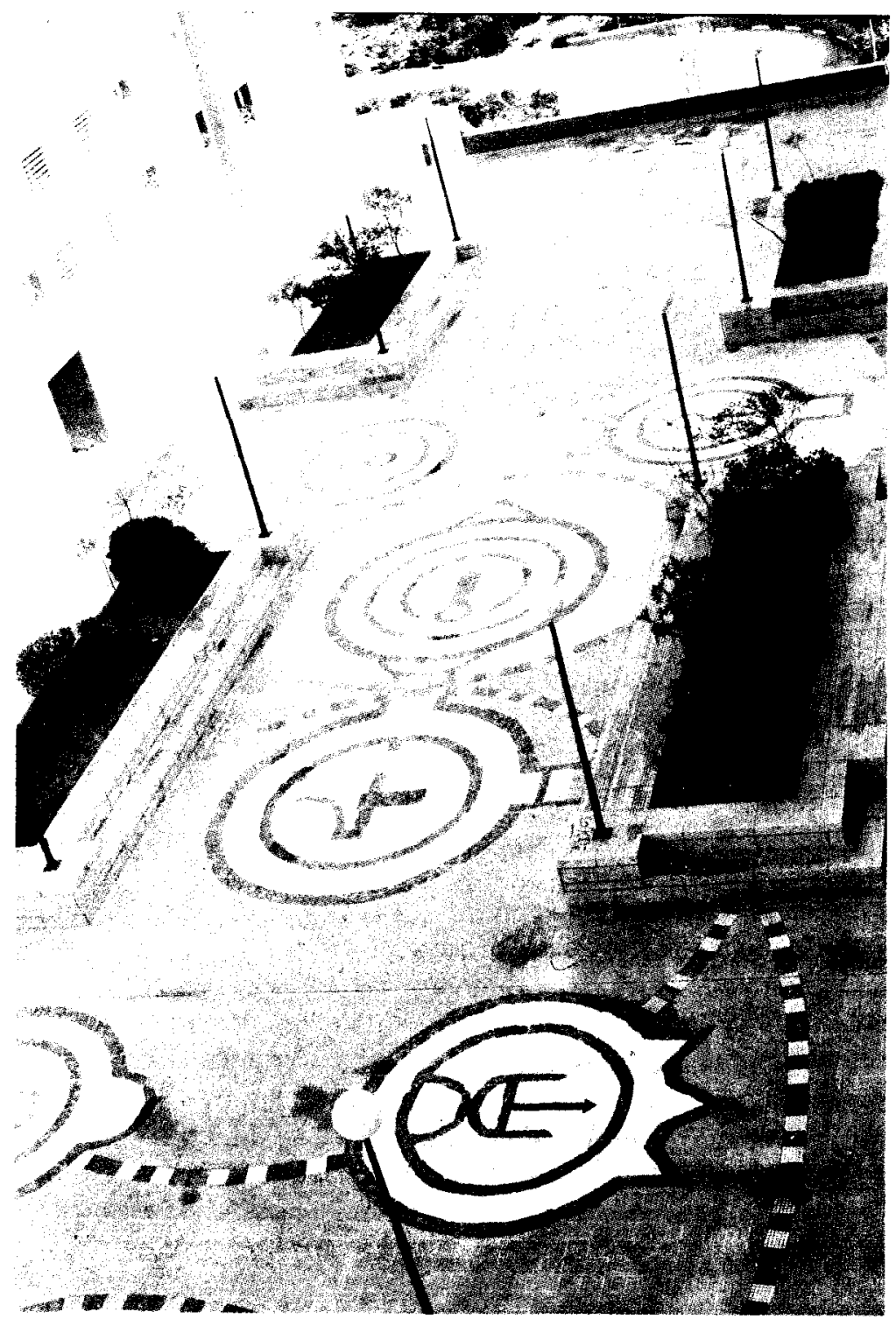

Fig. 17. Ceferino Moreno, Alegoria del orden cósmico 


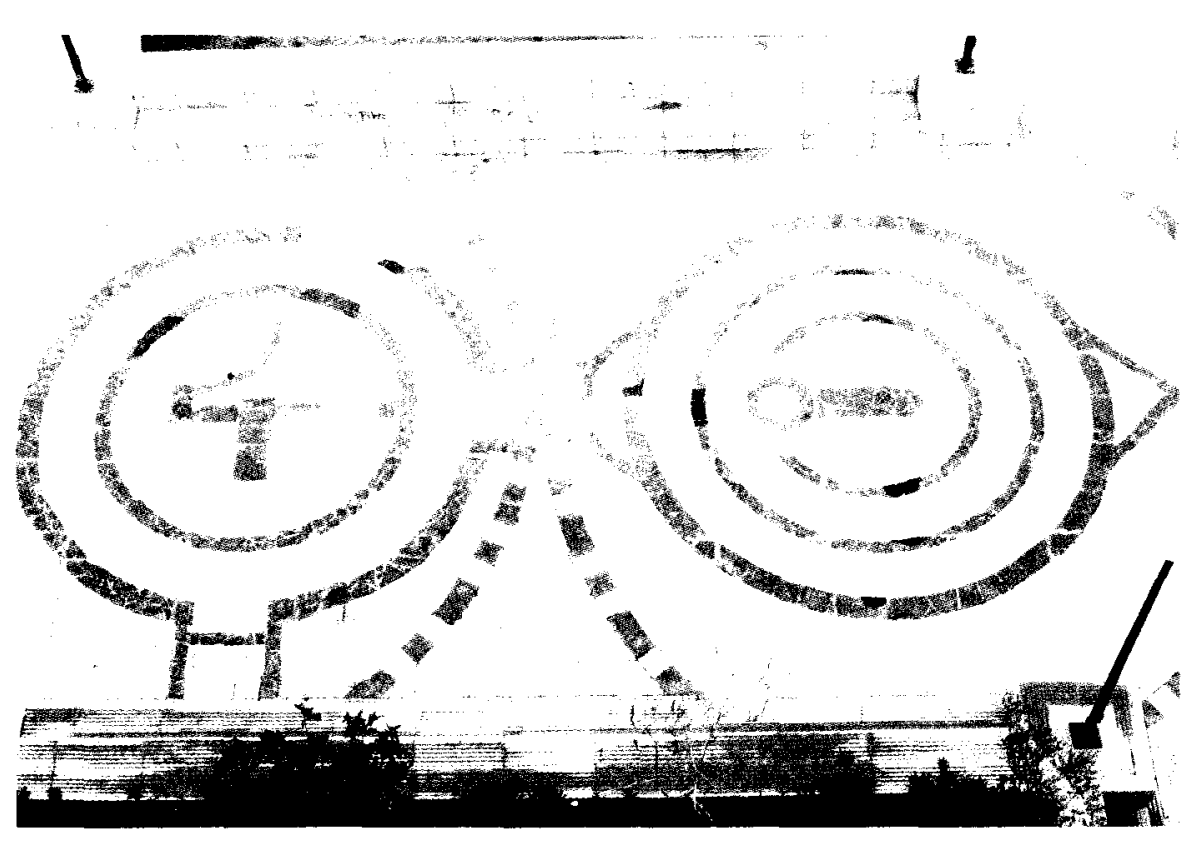

Fig. 18. Detalle

José Luis Pascual ha realizado tres mosaicos en 1991, que decoran la parte baja de la fachada de un edificio, orientada a dicha plaza. Esta obra, titulada Encuentro en el mar (fig. 19), no rompe con la estructura de la fachada, sino que se integra en ella al respetar tres espacios rectangulares rodeados por un marco-moldura blanco. En los laterales, de dimensiones más reducidas $(3,00 \times 1,40 \mathrm{~m})$, se ha representado una figura femenina en el de la izquierda, y otra masculina en el de la derecha; en el central, de mayor tamaño $(4,00 \times 1,40 \mathrm{~m})$, se produce el encuentro de los dos personajes (fig. 20).

José Luis Pascual, atraido por la obra de Antonio Gaudi en los bancos del Parque Güell de Barcelona, ha roto las piezas de mosaico para recomponerlas hasta originar estas tres composiciones, que tienen como protagonistas a la figura humana y al mar. Dichas composiciones presentan un claro sentido del volumen, de contornos precisos, definidos por lineas blancas, que adoptan ritmos curvilíneos, subrayando las tonalidades ocres y marrones de los cuerpos. La intensidad de los azules, blancos y naranjas, su marcada luminosidad, envuelve a la figura humana para sumergirla en un ambiente que evoca la presencia del agua del mar, la transparencia del cielo y la calidez de la arena, a través de la esencialidad de unas formas y de los grandes contrastes cromáticos. Una vez 

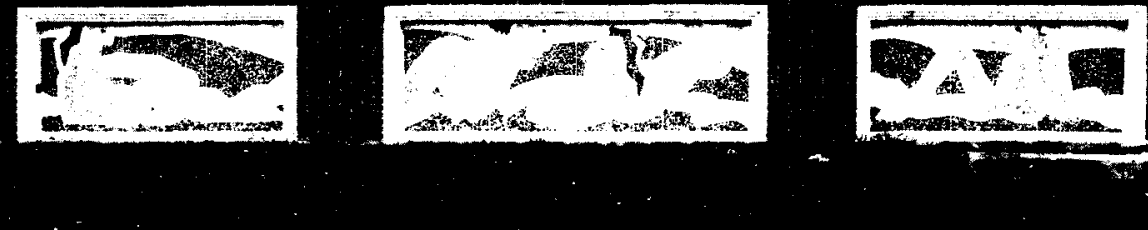

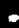

$+2$

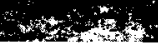
$\because 28$

Fig. 19. José Luis Pascual, Encuentro en el mar

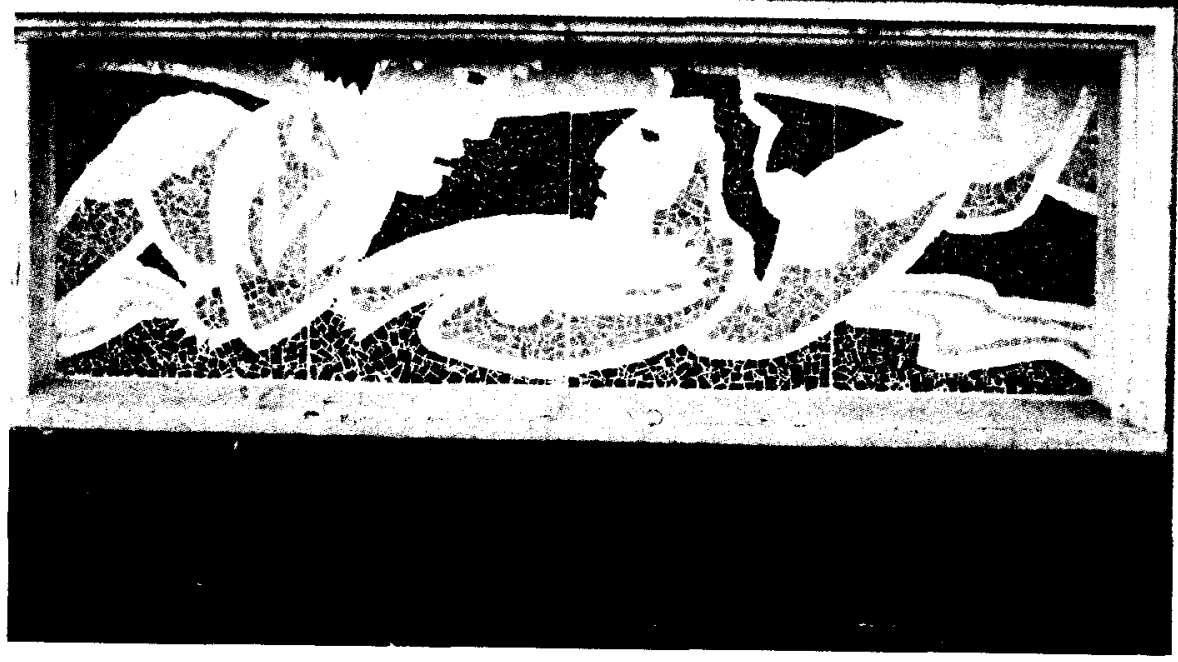

Fig. 20. Detalle 
más la materia, la forma y el color se combinan con su fuerza expresiva en una personal búsqueda del espacio plástico.

En su conjunto, este plan de ordenación urbana genera un discurso urbanistico, que implica la articulación de unos bloques de viviendas, relacionados con amplios espacios libres en los que la naturaleza se hace presente. La geometría de los edificios contrasta armónicamente con la reinterpretación de la naturaleza, una naturaleza sugerida por artificiales accidentes del suelo y por la presencia de una variedad de especies árboreas, que invitan al hombre a reencontrarla en medio del entorno urbano.

El espacio público se convierte de este modo en un lugar apto para la convivencia, pero también en el marco adecuado para la valoración de las formas plásticas, unas formas que, obedeciendo a una variedad de soluciones, han sido realizadas en diferentes materiales, alejándose conscientemente de la idea del tradicional monumento público, en la búsqueda de un mayor acercamiento al hombre. 
